\title{
0 Ensino de Psicologia na Graduação em Direito: uma Proposta de Interlocução
}

\author{
Teaching of Psychology for Graduation in Law: a Proposal for Interlocution \\ La Enseñanza de Psicología en la Graduación de Derecho: una Propuesta de Interlocución
}

\begin{abstract}
Laura Cristina Eiras Coelho Soares
Professora Adjunta de Psicologia Social do Departamento de Psicologia da Faculdade de Filosofia e Ciências Humanas da Universidade Federal de Minas Gerais- UFMG e do Programa de Pós-Graduação em Psicologia da UFMG.

Doutora e Mestre em Psicologia Social pela Universidade do Estado do Rio de Janeiro- UERJ
\end{abstract}

\section{Fernanda Simplício Cardoso}

Professora Assistente IV do Departamento de Psicologia da Pontifícia Universidade Católica de Minas Gerais- PUC Minas. Doutoranda em Psicologia Social pela Universidade do Estado do Rio de Janeiro- UERJ. Psicóloga Judicial do Tribunal de Justiça de Minas Gerais - TJMG. Especialista em Psicologia Jurídica pelo Conselho Federal de Psicologia - CFP

\section{Resumo}

Este estudo objetiva refletir sobre a construção e as tensões que marcam a relação da prática do ensino de Psicologia nos cursos de graduação em Direito. O objetivo principal é pensar em como estruturar um conteúdo programático que vise à concretização de uma prática profissional interdisciplinar. O diálogo entre a Psicologia e o Direito, expresso no campo específico, denominado neste trabalho de Psicologia Jurídica, trata da atuação em três principais áreas: Infância/Juventude, Família e Penal. Ao longo da história dessa interlocução, o trabalho do psicólogo jurídico foi sendo modificado e ampliado permitindo outras perspectivas de interação entre essas ciências. Desta forma, entende-se que o ensino de conteúdos da Psicologia no Direito deve contemplar essa diversidade de práticas e de possibilidades de trabalho conjunto.

Palavras-chave: Direito; ensino; interdisciplinaridade; Psicologia Jurídica.

Abstract

This article refers to the teaching of Psychology for graduation in Law. The main objective is to discuss the construction and the tensions that mark the relationship between these two fields of knowledge, by thinking how to structure a syllabus that seeks to achieve an interdisciplinary professional practice. The partnership between psychology and the Law, expressed in the specific field called Judicial Psychology refers to the work in three main areas: Childhood/ Youth, Family and Criminal. Throughout the history of this dialogue, the work of the judicial psychologist has been modified and expanded allowing other perspectives of interaction between these sciences. Thus, the teaching content of Psychology at Law school should include this diversity of practices and possibilities for joint work.

Keywords: Law School; education; interdisciplinarity; Judicial Psychology.

Resumen

Este estudio objetiva reflexionar sobre la construcción y las tensiones que marcan la relación de la práctica de la enseñanza de Psicología en los cursos de graduación em Derecho. El objetivo principal es pensar en como estructurar un contenido programático que objetive la concretización de una práctica profesional interdisciplinar. El diálogo entre la Psicología y el Derecho, expresado en el campo específico, denominado en este trabajo de Psicología Jurídica, trata de la actuación en tres principales áreas: Infancia/Juventud, Familia y Penal. A lo largo de la história de esa interlocución, el trabajo del psicólogo jurídico fue siendo modificado y ampliado permitiendo otras perspectivas de interacción entre esas ciencias. De esta forma, se entiende que la enseñanza de contenidos de la Psicología en el Derecho debe contemplar esa diversidad de prácticas y de possibilidades de trabajo conjunto.

Palabras clave: Derecho; enseñaza; interdisciplinaridad; Psicología Jurídica. 
A aproximação entre a Psicologia e o Direito não é recente e se relaciona com a própria história da Psicologia enquanto Ciência, conforme relatado por Brito (2012a). De acordo com Bock, Furtado, e Teixeira (2002), o status de Psicologia Científica é alcançado no final do século XIX, na Alemanha e, segundo Jacó-Vilela (1999), é nesse período que a Psicologia no ocidente se aproxima do Direito, investindo na produção de saberes e práticas psicológicas.

A compreensão do homem pelo Direito Moderno, como um sujeito universal, livre e racional, atrela-se ao que a Psicologia Positivista, no início, propôs-se a examinar (Jacó-Vilela, 1999). Na atualidade, outras vertentes teóricas da Psicologia dialogam com o Direito, tomando como objeto de estudo a subjetividade em sua relação com os contextos históricos, sociais, culturais, políticos e econômicos. No Brasil, a inserção da Psicologia no campo do Direito foi consolidada a partir do Estatuto da Criança e do Adolescente (Brasil, 1990), que prevê a "equipe interprofissional ou multidisciplinar" no âmbito jurídico para o atendimento dessa população. $\mathrm{O}$ reconhecimento do profissional de Psicologia para compor os serviços auxiliares de apoio ao juízo da infância e juventude foi um marco de consolidação da prática interdisciplinar nessa seara.

No entanto, anterior à legislação mencionada, os psicólogos já haviam iniciado suas atividades no judiciário realizando perícias e elaborando laudos, a fim de auxiliar na decisão dos juízes. Como ainda não haviam sido criadas as vagas para psicólogos nos tribunais, a inserção desse profissional ocorria com diferentes vinculações trabalhistas, tais como: perito designado por um juiz; assistente técnico contratado por uma das partes envolvidas no processo; funcionário de outra instituição cedido ao judiciário ou concursado do próprio Tribunal de Justiça desviado de função. Segundo Rovinski (2009), existiam também os serviços prestados por profissionais voluntários, como ocorreu no Estado de São Paulo, antes da realização do primeiro concurso que ocorreu em 1985.

O início da trajetória do psicólogo no sistema judiciário se deu no âmbito do Sistema Penal, e as principais demandas para o psicólogo foram de diagnóstico do criminoso e de elaboração de um prognóstico para subsidiar a decisão do magistrado sobre a progressão da pena, inclusive, incluindo-o nas equipes de perícias criminológicas, conforme assinalado por Rovinski (2009). Na área do Direito de Família, como também nas Varas da Infância e Juventude, o trabalho direcionado ao profissional da Psicologia era o de aferir quem teria melhores condições de exercer a guarda da criança ou adolescente envolvido naquele processo, como apresentado na obra de Brito (1993). Na atualidade, essas solicitações vêm sendo problematizadas, a fim de que a prática do psicólogo não se reduza a um instrumento jurídico para extração da verdade dos fatos, descompromissada com o contexto social e histórico de produção das subjetividades em jogo, e sem conexão com os princípios éticos que regem sua atividade profissional.

Destaca-se que o trabalho do psicólogo jurídico não se restringe àqueles profissionais lotados no judiciário, mas amplia-se a todos os psicólogos que trabalham junto ao sistema de justiça (Brito, 2011). De acordo com o Conselho Federal de Psicologia (2010), em documento produzido junto com o Centro de Referência Técnica em Psicologia e Políticas Públicas (CREPOP), "entende-se como psicólogos jurídicos não só aqueles que exercem sua prática profissional nos tribunais, mas também os que trabalham com questões diretamente relacionadas ao sistema de Justiça" (p.13). Nesse sentido, Brito (2012a) ressalva que fazem parte do sistema de justiça não só os psicólogos que possuem vínculo empregatício com o Poder Judiciário, mas todos aqueles que atuam em serviços afins, constituindo equipes de trabalho em locais como penitenciárias, instituições de acolhimento para crianças e adolescentes e nos estabelecimentos para execução de medidas socioeducativas aplicadas em adolescentes que praticaram ato infracional.

Além disso, esse crescimento da demanda judicial tem ultrapassado as práticas consolidadas no judiciário e, mais recentemente, alcançado os consultórios psicológicos particulares (Barreto \& Silva, 2011). Esses profissionais do âmbito 
clínico têm sido solicitados a confeccionarem documentos com fins judiciais ${ }^{1}$ ou a atuarem como assistentes técnicos ${ }^{2}$. Nesse aspecto, observa-se que os conhecimentos do campo da Psicologia Jurídica tornam-se relevantes para os psicólogos, até mesmo para aqueles que não escolheram esse ramo específico de atuação. Desta forma, diante das solicitações de cunho judicial terão domínio das implicações e limitações técnicas e éticas desse trabalho, tendo ferramentas inclusive para se posicionarem contrariamente aos pedidos de elaboração de laudos e para encaminharem essa demanda aos profissionais especializados. Para os bacharéis em Direito, o aprendizado propiciado pelo ensino da Psicologia Jurídica permite elucidar as atribuições do psicólogo jurídico e apontar as possibilidades de trabalho conjunto.

Diante do exposto, o presente artigo possui como objetivo refletir sobre as tensões e as temáticas que envolvem a interlocução entre o Direito e a Psicologia na atualidade, partindo do entendimento de que a elaboração dos conteúdos de Psicologia que são ensinados aos bacharéis em Direito deve contemplar esses debates e promover uma formação voltada para a atuação interdisciplinar. Nesse sentido, a escolha dos conteúdos abordados, na experiência docente aqui relatada, visou contribuir para a compreensão da relevância do trabalho interdisciplinar para a condução das demandas que chegam ao sistema de justiça. Essa proposta coaduna com o entendimento de Couto, Schimith, e DalbelloAraújo (2013) sobre a interdisciplinaridade "como uma possibilidade de contribuição para maior resolutividade dos problemas enfrentados, assim como para a identificação de um objeto comum a vários profissionais" (p. 503).

Para tal, o artigo se estrutura em dois momentos. Inicialmente apresentam-se alguns aspectos históricos que marcaram a aproximação entre esses dois campos de conhecimento e a problematização sobre os limites e as possibilidades de atuação do psicólogo no âmbito jurídico. Posteriormente, se esclarece como surgiu a inclusão do ensino da Psicologia nos currículos de graduação em Direito $^{3}$, apresentando-se uma experiência de ensino da disciplina de Psicologia lecionada para discentes do curso de bacharelado em Direito. A prática docente relatada encontra-se pautada na interdisciplinaridade própria da edificação da área da Psicologia Jurídica e na reflexão crítica sobre qual seria a contribuição da Psicologia para a formação em Direito. Nesta etapa também será detalhado o programa da disciplina e a bibliografia utilizada.

\section{A Psicologia Jurídica e suas perspectivas}

A fim de compreender os caminhos percorridos pelo psicólogo em sua prática no campo da justiça, faz-se necessário apontar alguns marcos que constituem a história desta relação entre Psicologia e Direito ${ }^{4}$. A primeira aproximação entre essas duas áreas de conhecimento, de acordo com

\footnotetext{
${ }^{1}$ Para maiores esclarecimentos sobre as possibilidades e limitações da atuação do psicólogo clínico no campo judicial recomenda-se a leitura das seguintes resoluções do Conselho Federal de Psicologia: Resolução do CFP nº 008/2010 que dispõe sobre a atuação do psicólogo como perito e assistente técnico no Poder Judiciário e Resolução do CFP 007/2003 que versa sobre a elaboração de documentos.

${ }^{2}$ O Novo Código de Processo Civil - Lei 13.105/15 estabelece os critérios para participação dos assistentes técnicos nas perícias judiciais.

${ }^{3}$ Mais adiante serão apresentadas as normativas do Ministério da Educação que exigiram a inclusão da disciplina de Psicologia nos currículos de graduação dos cursos de Direito no país.

${ }^{4}$ No presente artigo não se propõe estabelecer a história da Psicologia Jurídica, mas apenas utilizar informações dessa trajetória para se refletir sobre as mudanças ocorridas e seus efeitos na parceria entre Direito e Psicologia.
} 
Jacó-Vilela (1999), resultou em pesquisas sobre a Psicologia do Testemunho, que tinham como referência a procura por uma Psicologia científica e probatória. Nesse cenário, no qual a concepção era de um trabalho pericial, eram aplicados e construídos métodos de mensuração visando à obtenção de dados precisos quanto à veracidade dos testemunhos envolvidos no processo. Um dos principais autores representantes desta perspectiva da Psicologia Jurídica foi Mira y López que publicou em espanhol, no ano de 1945, o livro intitulado Manual da Psicologia Jurídica ${ }^{5}$.

Desta forma, consonante com a história da própria Psicologia enquanto ciência observa-se que se tratava de uma Psicologia Jurídica com influência positivista. De acordo com essa perspectiva, os fenômenos sociais eram categorizados e sistematizados seguindo os métodos das Ciências da Natureza com seus princípios de neutralidade, objetividade, universalismo e a-historicismo (Brito, 1993). Brito (1993) relata que os métodos utilizados pelas chamadas Ciências da Natureza foram aplicados ao objeto das Ciências Humanas e Sociais em busca de seu reconhecimento científico.

A partir da segunda metade do século passado, observou-se o crescimento de uma Psicologia crítica, que considerava o caráter histórico dos fenômenos psicológicos e a produção de subjetividades visando à transformação social. Essa corrente provocou uma mudança da concepção de homem e de método e, como indicam Mancebo, Jacó-Vilela, e Rocha (2003), os pilares dos métodos das Ciências Naturais que eram aplicados à Psicologia foram sendo questionados. No campo da Psicologia Jurídica, a perícia psicológica que seguia o modelo positivista foi sendo problematizada a partir de uma compreensão sócio-histórica dos sujeitos envolvidos no processo e das solicitações judiciais. Sobre esta passagem, Brito (1993) revela a procura por "um modelo de Ciência que não esteja necessariamente atrelado à verificação experimental e que começa a ser reivindicado, visando uma melhor compreensão dos diversos objetos de estudo das Ciências Humanas e Sociais" (p. 37). Esta inquietação também reverbera no espaço jurídico como pode ser notado no seguinte trecho:

(...) como o psicólogo aceitará/atuará frente a esse encargo: será o estrito avaliador da intimidade, aperfeiçoando seus métodos de exame? Ou lembrar-se-á que este sujeito singular também é um sujeito-cidadão, cujos direitos e deveres se constituem no espaço público, território onde perpassam outros discursos e práticas que não o exclusivamente psicológico? (Jacó-Vilela,1999, p. 17).

O campo da Psicologia Jurídica permanece na busca pela consolidação de outros espaços, para além da perícia psicológica, que permitam ampliar sua contribuição para o Sistema de Justiça. No entanto, assim como acontece na ciência psicológica como um todo, na Psicologia Jurídica uma perspectiva teórica não supera nem substitui a outra, mas ambas passam a coexistir (Rey, 2001).

Esse aspecto histórico mostra-se importante no ensino de Psicologia para graduandos em Direito, na medida em que, os instrumentos psicológicos são questionados em sua cientificidade pelos tribunais. Por vezes, há uma tendência por parte dos operadores do direito em aceitar como informação válida somente o material psicológico oriundo de avaliação expressa em dados quantitativos. Os discentes, por sua vez, inicialmente demonstram a compreensão de que a mensuração quantitativa dos dados elimina ou reduz o que denominam de aspecto subjetivo dos laudos psicológicos. Logo, parece relevante retomar com os estudantes de Direito um antigo debate metodológico sobre Ciências Naturais e Exatas e Ciências Humanas e Sociais ${ }^{6}$, que permanece vivo na representação social sobre as ferramentas psicológicas.

$\mathrm{Na}$ atualidade, o debate a respeito da relação interdisciplinar entre a Psicologia e o Direito se expressa em dois eixos principais: a demanda

\footnotetext{
${ }^{5}$ Em português, a primeira edição data de 1955.

${ }^{6}$ Para essa discussão recomenda-se a leitura de DEMO, Pedro. Introdução à metodologia da ciência. São Paulo: Atlas,1987.
} 
da Justiça e a construção da prática profissional do psicólogo jurídico. Diversos autores (Brito, 1993; Coimbra, 2000; Verani, 1994) preocupam-se com o caráter normativo e o conteúdo repressivo que podem estar presentes neste diálogo. Os três grandes campos de atuação do psicólogo dentro da justiça, a saber: a Infância e Juventude, o Sistema Penal e a Vara de Família apresentam problemáticas próprias. Contudo, independentemente da área específica, os profissionais compartilham o mesmo questionamento: Quais são os limites e as possibilidades da atuação do psicólogo nesse espaço de trabalho interdisciplinar?

Em todos os setores da justiça, a demanda direcionada ao psicólogo ainda chega mergulhada em um conteúdo avaliador, investigativo e com a concepção de que esse perito reportará ao magistrado respostas definitivas e conclusivas com valor de verdade. O profissional psicólogo deve questionar-se sobre os desdobramentos e as questões éticas para os envolvidos naquele processo, dos conteúdos expressos em um laudo no âmbito jurídico. Sobre a elaboração da avaliação psicológica judicial, Barreto e Silva (2011) destacam dois modos de solicitações: a de construção de uma verdade sobre um fato ocorrido e a de predição de um comportamento. No entanto, a verdade que o Direito tradicionalmente busca refere-se à verdade objetiva, à verdade dos fatos, enquanto a Psicologia considera a pluralidade de verdades, aquela do sujeito atendido: a verdade subjetiva. Como esclarece Arantes (2008): “(...) nas práticas psi, as fantasias, erros, lapsos, esquecimentos, sonhos, pausas, silêncios e contradições não são entendidas como sendo opostos à verdade" (p.13). O Direito busca o trabalho do perito visando elucidar essa verdade objetiva. Diante desse impasse mostra-se como uma importante tarefa ao docente desconstruir esse imaginário e edificar outra possibilidade de contribuição da Psicologia ao Direito.

Quando se pensa a respeito da função de um parecer e de quais informações podem compor um laudo, deve-se refletir sobre o que é demandado pelo judiciário e questionar-se sobre qual seria a contribuição ético-técnica que o psicólogo poderia oferecer. Perante essas indagações encontram-se múltiplas respostas que têm sido alvo de constantes debates dentro do campo da Psicologia Jurídica, dada à diversidade de posturas decorrentes das diferentes correntes teóricas identificadas na referida área de conhecimento. A Psicologia Jurídica encontra respaldo teórico em abordagens e áreas como a Avaliação Psicológica (Lago, 2009; Rovinski, 2009; Shine, 2005 ), a Psicanálise (Barros-Brisset, 2010; Groeninga \& Pereira, 2003) e a Psicologia social (Arantes, 2008; Brito,1993; 2008a ).

Seguindo a vertente que dialoga com a Psicologia Social, entende-se que a Psicologia Jurídica deve buscar superar "(...) a visão reducionista que muitas vezes conduz à patologização individual de casos que são na verdade sociais" (Brito, 1993, p. 21). A partir dessa perspectiva, compreendese que os psicólogos no sistema de justiça devem definir qual o trabalho que desenvolvem e qual contribuição podem oferecer ao judiciário, não perdendo o posicionamento crítico necessário para avaliar a natureza das demandas jurídicas e a real possibilidade de atendê-las. Contudo, Arantes (2008) alerta que se encontra presente na Psicologia Jurídica um novo mal-estar. A autora pontua que além dessas inquietações sobre o fazer do psicólogo jurídico e sua subordinação às solicitações judiciais, encontra-se a perda dos limites de cada uma das áreas de conhecimento. Esse aspecto decorre da criação, pelo judiciário, de práticas jurídico-legais que interferem no campo da Psicologia e comprometem sua autonomia, conforme evidenciado em “(...) programas que definem o tratamento como pena, a justiça como terapêutica e o depoimento como sem dano programas estes nos quais o psicólogo vem sendo designado para atuar de maneira, a nosso ver, conflitante com a sua formação profissional" (p.133).

Desta maneira, o ensino de conteúdos da Psicologia para formação em Direito deve ser elaborado respeitando-se seu caráter interdisciplinar, a fim de que uma área não se reduza a outra. De acordo com Leis (2005), "a prática interdisciplinar é contrária a qualquer 
homogeneização e/ou enquadramento conceitual" (p.3). Para este autor, a interdisciplinaridade resulta de um trabalho singularizado e de múltiplas facetas. Pode-se, constatar, com Brito (2012b) que “(...) o trabalho interdisciplinar não significa que todas as disciplinas devam ter o mesmo olhar, ou chegar às mesmas conclusões sobre certo tema. É na diversidade de visões, nas distintas possibilidades de análise e de compreensão das questões que a interdisciplinaridade se dá" (p. 567). Na prática docente a ser relatada, a escolha das temáticas e do referencial bibliográfico, que foram ensinados aos discentes em Direito, teve em seu cerne essa preocupação em destacar como se desenvolve a prática interdisciplinar da Psicologia junto ao sistema de justiça.

\section{O ensino de Psicologia no curso de Direito: relato de um caminho percorrido}

A inclusão do ensino de Psicologia no curso de Direito encontra-se apoiada no art $5^{\circ}$ da Resolução CNE/CES n ${ }^{\circ}$ 9, de 29 de setembro de 2004 que institui as Diretrizes Curriculares Nacionais do Curso de Graduação em Direito e dá outras providências:

Art. $5^{\circ} \mathrm{O}$ curso de graduação em Direito deverá contemplar, em seu Projeto Pedagógico e em sua Organização Curricular, conteúdos e atividades que atendam aos seguintes eixos interligados de formação: I - Eixo de Formação Fundamental, tem por objetivo integrar o estudante no campo, estabelecendo as relações do Direito com outras áreas do saber, abrangendo dentre outros, estudos que envolvam conteúdos essenciais sobre Antropologia, Ciência Política, Economia, Ética, Filosofia, História, Psicologia e Sociologia.

Além do ensino obrigatório de Psicologia para a graduação, os conteúdos psicológicos despertam interesse dos discentes em Direito ao tomarem ciência de sua inclusão nos concursos para magistrados em função da Resolução $\mathrm{n}^{\circ}$ 75/2009 do Conselho Nacional de Justiça. No referido documento, que trata sobre os concursos públicos para ingresso na carreira da magistratura em todos os ramos do Poder Judiciário nacional, consta que nas etapas de prova escrita e exame oral serão contemplados conteúdos da formação humanística, incluindo nesse grupo o que denominaram de Psicologia Judiciária ${ }^{7}$. Nos cursos de graduação em Direito, a disciplina pode se apresentar com diferentes denominações, tais como: Psicologia, Psicologia aplicada ao Direito, Psicologia Jurídica, dentre outras. A carga horária determinada também irá se modificar de acordo com a grade curricular do curso.

A experiência a ser detalhada refere-se à docência ${ }^{8}$ em uma instituição de ensino de educação superior privada, no ensino da disciplina obrigatória denominada Psicologia, ofertada para o sexto período da graduação em Direito, com carga horária de $34 \mathrm{~h} / \mathrm{a}$. Apesar do título da matéria ser apenas Psicologia, a ementa direcionava para a interface da Psicologia com o Direito, mas de forma abrangente, possibilitando a elaboração de um curso com temáticas diversificadas no âmbito da Psicologia Jurídica. O objetivo consistiu em formar profissionais com uma postura críticareflexiva sobre a sociedade e em preparar o discente para o trabalho interdisciplinar junto às equipes que compõem o sistema de justiça.

\footnotetext{
${ }^{7}$ Caberia uma análise e problematização a respeito dos tópicos que compõem o conteúdo de Psicologia Judiciária que consta na Resolução n ${ }^{\circ} 75 / 2009$ do CNJ. Contudo, esse debate não constitui o objetivo do presente artigo e, portanto, optou-se por apenas mencionar a questão a fim de que suscite o interesse do leitor.

${ }^{8}$ As autoras do presente artigo trabalharam conjuntamente na construção do conteúdo da disciplina, já que uma encontrava-se na condição de titular da matéria, enquanto a outra atuou como professora substituta durante um ano. Contudo, a disciplina foi ganhando novos aportes metodológicos ao longo dos semestres lecionados que também foram incluídos nesse relato.
} 
No momento da elaboração da referida disciplina, surgiram algumas indagações: Quais conteúdos de Psicologia seriam relevantes para a formação de um operador do Direito? Qual seria o objetivo dessa disciplina? Seria instrumentalizar os graduandos em Direito, fornecendo ferramentas da Psicologia para sua atuação? Isso é desejável ou mesmo ético de ser feito? Não seria uma banalização dos conteúdos da Psicologia? Diante do histórico apresentado sobre a parceria da Psicologia com o Direito, será que não seria uma oportunidade de apresentar esse mal-estar e as tensões existentes nessa interface? Assim, buscou-se transformar essa aplicação da Psicologia ao Direito em um ensino contextualizado com a prática jurídica, no intuito de mostrar uma atuação da Psicologia no âmbito jurídico, apoiada técnica, ética e politicamente em um projeto de transformação social.

A partir dos questionamentos apontados, o conteúdo programático foi estruturado em duas partes. Uma etapa introdutória que apresentou o percurso histórico da Psicologia e suas principais correntes de pensamento, utilizando-se como referência alguns capítulos do livro intitulado Psicologias (Bock et al., 2002). Os discentes apresentaram dúvidas sobre o campo da Psicologia, revelando-se como um momento propício para desconstruir estereótipos e preconceitos sobre a atuação do psicólogo e a construção desse saber. No decorrer da disciplina, diversos recursos metodológicos foram utilizados visando à apreensão do conteúdo pelo discente, tais como: filmes, vídeos institucionais, reportagens televisionadas, estudo dirigido, estudos de caso, atividades interdisciplinares, como o debate intercurso e a prática investigativa.

Após essas primeiras aulas que estabeleceram o cenário da Psicologia como ciência e profissão, começou a segunda parte do curso no qual foram apresentados os conteúdos específicos da interface entre Psicologia e Direito. Nesta fase da disciplina, inicialmente relatou-se a construção histórica da aproximação entre Psicologia e Direito e foram utilizados, como referência, autores de diferentes enfoques da Psicologia Jurídica (Brito, 2012a;
Lago, 2009; Rovinski, 2009 ) e da área do Direito (Verani, 1994).

Ainda na introdução da disciplina, decidiu-se incluir algumas contribuições da Psicologia para a magistratura, em decorrência da inclusão da Psicologia Jurídica nos editais de concurso para o cargo de magistrado. Os textos de referência foram Groeninga (2002) e Prado (2003), a fim de contemplar alguns dos tópicos presentes da Resolução n ${ }^{0}$ 75/2009 do CNJ. Sobre a discussão a respeito da inserção do psicólogo no Judiciário foram relatadas as modalidades de perícias psicológicas e suas implicações éticas (Shine, 2005).

Posteriormente, foram trabalhadas as intervenções psicossociais no atendimento das demandas judiciais nos três principais eixos: Penal/Criminal, Infância e Juventude, Família. Sobre o campo criminal foi problematizada a contribuição da Psicologia aplicada ao Sistema Penal, especificamente no que tange à demanda da realização do exame criminológico e o debate geradosobre a atuação do psicólogo no sistema prisional (Bandeira, Camuri, \& Nascimento, 2011). Nesse ponto, são mencionadas outras possibilidades de trabalho do psicólogo junto à população carcerária, dando destaque às práticas compromissadas com a ética profissional, visando à promoção da dignidade, da igualdade e da integridade do ser humano. $\mathrm{Na}$ área penal existe uma temática que provoca a curiosidade dos discentes e que alcançou o espaço midiático, tratase do diagnóstico de psicopatia. Para fundamentar a discussão e suscitar o pensamento reflexivo foi escolhido o texto de Rauter (2007), que se posiciona criticamente sobre a aplicação do teste PCL-R, instrumento usado para diagnosticar esse quadro e, ainda, propõe outros modos de inserção do psicólogo nas prisões. Além disso, explanou-se sobre a problemática do portador de sofrimento mental na justiça, considerando os aspectos cíveis (interdição e curatela) e criminais (inimputabilidade e medida de segurança) envolvidos.

No que tange à infância e juventude iniciouse com a apresentação de legislações acerca da 
área mencionada, relacionando-as com o saber psicológico a respeito da temática. Logo, foram mencionados alguns artigos do Estatuto da Criança e Adolescente (Brasil,1990) e da Lei $n^{\circ}$ 12.010/09, conhecida como nova lei da adoção. Os temas abordados foram: adolescente em conflito com a lei (Arantes, 2015; Volpi, 1997) tendo como suporte o posicionamento do Conselho Federal de Psicologia - que é contrário à redução da maioridade penal; violência contra criança (Gonçalves, 2003); questões psicológicas que envolvem a adoção e a prática com grupos na habilitação para adoção (Bloris, Coimbra, \& Moreira, 2000; Weber, 2011); a escuta de crianças na justiça e o polêmico depoimento sem dano (Brito, 2012c).

Sobre a área da Família, foi discutida a guarda compartilhada a partir de argumentos da Psicologia que refutam as decisões encontradas em jurisprudências que negaram o pedido dessa modalidade de convivência familiar após divórcio (Brito \& Gonsalves, 2013). Para a compreensão dessa fundamentação foi importante trabalhar os conceitos de conjugalidade e parentalidade, estabelecendo sua distinção, bem como desdobramentos do pós-divórcio para os pais e para os filhos. No cenário de litígio após separação conjugal surge a discussão sobre a prática da alienação parental. Em busca de problematizar a aplicação da lei $n^{\circ} 12.318 / 2010$, que versa sobre a alienação parental, utilizou-se o artigo de Sousa e Brito (2011). Outro ponto relevante refere-se às novas configurações familiares que chegam aos tribunais, sejam as famílias recasadas, ou seja, com padrasto e/ou madrasta (Soares, 2015), sejam as famílias homoparentais (Uziel, 2007).
O aporte teórico usado na disciplina deu suporte para o desenvolvimento de atividades didáticas que visaram marcar o campo de interface entre Psicologia e Direito. Dentre os métodos empregados, menciona-se a prática investigativa e o debate intercurso. A prática foi realizada em diversos contextos de atuação do psicólogo jurídico. Nesta atividade, os alunos foram distribuídos em pequenos grupos e encaminhados às instituições que compõem o sistema de justiça, com o objetivo de entrevistar os profissionais da área do Direito e da Psicologia, a fim de compreender como se efetiva essa parceria interdisciplinar. O roteiro das entrevistas foi construído com auxílio docente e adaptado para cada contexto específico.

O debate intercurso reuniu alunos de graduação de Psicologia e Direito, ambos cursando a disciplina Psicologia Jurídica, para discutirem os aspectos sociais, psicológicos e jurídicos envolvidos em um processo de adoção. Primeiramente, o caso foi apresentado aos alunos e, posteriormente, as questões foram debatidas em grupo, privilegiando a perspectiva interdisciplinar para o entendimento do caso. Além disso, cabe destacar que a universidade a qual pertence o curso de direito em que foi ministrada a disciplina, de acordo com sua natureza e consoante às normativas educacionais vigentes, estabelece a interdisciplinaridade como um dos fios condutores da formação do aluno. Diante do exposto, buscouse, ao longo da disciplina, traçar um panorama para os futuros bacharéis em Direito a respeito da participação da Psicologia no sistema de justiça e seus atravessamentos éticos, políticos, sociais e históricos.

\section{Considerações Finais}

A proposta apresentada mostra-se como uma possibilidade de caminho metodológico de ensino, dentro da diversidade que é o campo da Psicologia Jurídica. Entende-se que esse percurso reflete também a formação específica do docente que constrói a estrutura da disciplina a partir de seu referencial teórico e posicionamento ético.
As temáticas escolhidas buscaram contemplar as três principais áreas de atuação do psicólogo jurídico - Infância e Juventude, Família e Penaldentro de uma visão que prioriza o campo social. Contudo, em decorrência da limitação da carga horária da disciplina, outros conteúdos que certamente poderiam ser ofertados não foram 
inseridos. Podem-se citar algumas discussões extremamente relevantes, tais como: a judicialização das relações sociais; a resolução nãoadversarial de conflitos (mediação e conciliação); os estudos sobre vitimologia; a aplicação da lei Maria da Penha e os trabalhos desenvolvidos com homens autores de violência; a contribuição da Psicologia Jurídica junto à Segurança Pública; os debates sobre Direitos Humanos; a atuação do psicólogo nas varas do idoso e na justiça do trabalho, dentre outros.

Assim, com base em uma perspectiva que privilegia o ponto de vista da Psicologia Social no âmbito jurídico, foi selecionado o referencial bibliográfico a ser trabalhado na disciplina de Psicologia ofertada para o curso de graduação em Direito. A construção dessa proposta de ensino teve como cerne o preparo dos discentes para as práticas interprofissionais que se darão no ambiente do sistema de justiça, especificamente, no contato com o ramo da Psicologia que se insere nesse âmbito: a Psicologia Jurídica. No entanto, sabe-se da necessidade de se incluir experiências de campo que possam estabelecer essa aproximação entre Psicologia e Direito, a fim de que os alunos vivenciem os desafios - alguns deles expostos ao longo do presente artigo - presentes nessa parceria interdisciplinar. Nesse sentido, sugere-se que sejam elaboradas atividades atreladas ao projeto da disciplina que desenvolvam essa interface, tais como a prática investigativa e o debate intercurso mencionados nesse relato. Além disso, projetos de extensão universitária que integrem discentes da Psicologia e do Direito, assim como docentes de ambos os cursos, mostram-se como caminho fundamental para a consolidação dessa articulação interdisciplinar.

Em resposta aos questionamentos levantados ao longo desse artigo entende-se que, independentemente do referencial teórico adotado pelo docente, espera-se que o diálogo interdisciplinar prevaleça na metodologia de ensino da disciplina, a fim de promover um conhecimento integrado e capaz de compreender toda a complexidade envolvida nos fenômenos humanos e sociais. Para tanto, conclui-se que dois aspectos devem ser observados. Primeiro, é necessário que operadores do direito e psicólogos respeitem o exercício profissional de cada área, não havendo uma relação de subordinação no campo do saber, mesmo em condições onde vigore uma hierarquia institucional definidora das relações de trabalho. As posições epistemológicas das áreas do Direito e da Psicologia são distintas, todavia, o compromisso ético de respeitá-las é comum a ambas. Por fim, é importante ao psicólogo, que decide trabalhar na interface com a justiça, buscar uma formação específica para desenvolver as competências necessárias, visando abarcar a diversidade de demandas que existe na atuação do psicólogo jurídico. Essa observação se estende ao docente que se propõe a lecionar a referida disciplina nos cursos de direito sem ter cursado, estudado ou praticado a Psicologia Jurídica. O mesmo pode ser dito em relação ao bacharel em direito, cuja formação não oferece embasamento para o ensino de uma disciplina específica do campo da Psicologia. Entende-se essa situação como não desejável, tendo em vista que pode gerar um debate inócuo ou desarticulado a ponto de comprometer o ensino da Psicologia Jurídica e seu desenvolvimento enquanto campo de saber e prática.

\section{Referências}

Arantes, E. M. de M. (2015). Considerações sobre as propostas de redução da maioridade penal e agravamento da medida socioeducativa de internação. In J. L. Q. Magalhães, M. J. G., Salum, \& R. T. Oliveira (Orgs). Mitos e Verdades Sobre a Justiça Infanto Juvenil Brasileira: Por que Somos Contrários à Redução da Maioridade Penal? (pp.109-119). Brasília: CFP.
Arantes, E. M. de M. (2008). Mediante quais práticas a psicologia e o direito pretendem discutir a relação? Anotações sobre o mal-estar. In C. M. B. Coimbra, et al. PIVETES: Encontros entre a Psicologia e o Judiciário(pp. 131-148) Curitiba: Juruá.

Bandeira, M. M. B., Camuri, A. C., \& Nascimento, A. R. (2011). Exame criminológico: uma questão ética para 
a psicologia e para os psicólogos. Revista Mnemosine, 7(1), p. 27-61. Recuperado de http://www.mnemosine. com.br/ojs/index.php/mnemosine/article/view/213/ pdf_198

Barreto, N. A. \& Silva, P. R. da M. (2011). Laudo psicológico? Reflexões ético-metodológicas sobre a dispersão das práticas psicológicas no judiciário. Revista Mnemosine, 7(1), 2-26.

Barros-Brisset, F. O. de. (2010). Um dispositivo conector Relato da experiência do PAI-PJ/TJMG, uma política de atenção integral ao louco infrator, em Belo Horizonte. Revista Brasileira de Crescimento e Desenvolvimento Humano, 20(1), 116-128. Recuperado de http://pepsic. bvsalud.org/pdf/rbcdh/v20n1/16.pdf

Bloris, D. A., Coimbra, J. C., \& Moreira, M. de C. (2000). Da responsabilidade pela escolha da filiação: o grupo de habilitação para adoção da I Vara da infância e juventude do Rio de Janeiro. In Anais do I Encontro de Psicólogos jurídicos do Tribunal de Justiça do Estado do Rio de Janeiro (pp.103-110).

Bock, A. M. B., Furtado, O., \& Teixeira, M. de L.T. (2002). Psicologias: uma introdução ao estudo de psicologia. $13 \mathrm{ed}$. São Paulo: Saraiva.

Brasil. Lei $n^{\circ} 8.069$ de 13 de julho de 1990. Dispõe obre o Estatuto da Criança e do Adolescente e dá outras providências. Brasília, DF: Palácio do Planalto.

Brito, L. M. T. de. (1993). Se-pa-ran-do:um estudo sobre a atuação do psicólogo nas Varas de Família. Rio de Janeiro: Relume-Dumará/ UERJ.

Brito, L.M.T. de (Org.). (2008). Famílias e separações: perspectivas da Psicologia Jurídica. Rio de Janeiro: Eduerj.

Brito, L. M. T. de. (2011). Avaliação psicológica no contexto das instituições de justiça. Em Conselho Federal de Psicologia. (Org.). Ano da Avaliação Psicológica - Textos geradores. v. 1. (pp. 85-88). Brasília.

Brito, L. M. T. de. (2012a). Anotações sobre a Psicologia Jurídica. Psicologia: Ciência e Profissão, 32(esp.), 194-205. Recuperado de http://www.scielo.br/pdf/pcp/v32nspe/ v32speca14.pdf

Brito, L. M. T. de. (2012b).O sujeito pós-moderno e suas demandas judiciais. Revista Psicologia: Ciência e Profissão, 32(3), 564-575. Recuperado de http://www.scielo.br/ pdf/pcp/v32n3/v32n3a04

Brito, L. M. T. de (Org.). (2012c). Escuta de Crianças e adolescentes: reflexões, sentidos e práticas. Rio de Janeiro: EdUERJ.

Brito, L. M. T. de \& Gonsalves, E. N. (2013). Guarda compartilhada: alguns argumentos e conteúdos da jurisprudência. Revista Direito FGV, 9(1), 299-318. Recuperado de http://bibliotecadigital.fgv.br/ojs/index. $\mathrm{php} /$ revdireitogv/article/view/20925/19653

Coimbra, J. C. (2000). O que faz o psicólogo jurídico? A construção de uma narrativa como questão preliminar. In Anais do I Encontro de Psicólogos Jurídicos do Tribunal de Justiça do Estado do Rio de Janeiro (pp. 27-32).
Conselho Federal de Psicologia. (2010). Referências técnicas para atuação do psicólogo em Varas de Família. - Brasília: CFP.

Conselho Nacional de Justiça. Resolução $n^{0} 75$, de 12 de maio de 2009. Dispõe sobre os concursos públicos para ingresso na carreira da magistratura em todos os ramos do Poder Judiciário nacional. Recuperado de http:// www.cnj.jus.br//images/atos_normativos/resolucao/ resolucao_75_12052009_27112015155433.pdf

Couto, L. L. M., Schimith, P. B., \& Dalbello-Araujo, M. (2013). Psicologia em ação no SUS: a interdisciplinaridade posta à prova. Psicologia: Ciência e Profissão, 33(2), 500-511. doi: 10.1590/S1414-98932013000200018

Gonçalves, H. S. (2003). Infância e Violência no Brasil (pp. 144-168). Rio de Janeiro: NAU Editora; FAPERJ.

Groeninga, G. O estresse no exercício do direito de família a angústia no judiciário. (2002). In R. da C. Pereira (Coord.). III CongressoBrasileiro de Direito de Família: Família e cidadania - o novo CCB e a vacatio legis(pp.475-488). Belo Horizonte: IBDFAM/Del Rey.

Groeninga, G. C., \& Pereira, R. (Orgs.). (2003). Direito de família e psicanálise: rumo a uma nova epistemologia. Rio de Janeiro: Imago.

Jacó-Vilela, A. M. (1999). Introdução: Os primórdios da Psicologia Jurídica. In L.M.T de Brito (Org.). Temas de Psicologia Jurídica (pp.11-18). Rio de Janeiro: Editora Relumé-Dumará.

Lago, V. de M., Amato, P., Teixeira, P.A., Rovinski, S.L.R., \& Bandeira, D.R. (2009). Um breve histórico da psicologia jurídica no Brasil e seus campos de atuação. Estudos de psicologia (Campinas), 26(4), 483-491.

Leis, H. R. Sobre o conceito de interdisciplinaridade. (2005). Cadernos de Pesquisa Interdisciplinar em Ciências Humanas, 6(73), 1-23. Recuperado de https://periodicos.ufsc.br/ index.php/cadernosdepesquisa/article/view/2176/4455

Mancebo, D., Jacó-Vilela, A. M., \& Rocha, M. L. (Orgs.). (2003). Psicologia social: Relatos na América Latina. São Paulo: Casa do Psicólogo.

Ministério da Educação. Resolução CNE/CES n 9, de 29 de setembro de 2004. Recuperado de http://portal.mec.gov. br/cne/arquivos/pdf/rces09_04.pdf

Prado, L. R. de A. (2003). Neutralidade e imparcialidade dos juízes?. In G.C. Groeninga \& R. Pereira (Orgs.). Direito de família e psicanálise: rumo a uma nova epistemologia (v. 1, pp. 301-309). Rio de Janeiro: Imago.

Rauter, C. (2007). Clínica e estratégias de resistência: perspectivas para o trabalho do psicólogo em prisões. Psicologia \& Sociedade, 19(2), 42-47.

Rey, F. G. (2001). Os desafios teóricos da Psicologia Social e suas implicações para as ações e o compromisso social. In Â. M.P. Caniato \& E. A. Tomanik.Compromisso Social da Psicologia (pp.27-59). Porto Alegre: ABRAPSOSUL.

Rovinski, S. Psicologia jurídica no Brasil e na América Latina. (2009). In S. Rovinski \& R. Cruz.Psicologia jurídica: perspectivas teóricas e processos de intervenção (pp. 1122). São Paulo: Vetor. 
Shine, S. Avaliação psicológica no contexto forense. (2005). EmS. Shine.Avaliação psicológica e lei: adoção, vitimização, separação conjugal dano psíquico e outros temas (pp.1-18). São Paulo: Casa do psicólogo.

Soares, L. C. E. C. (2015). Pais e mães recasados: vivências e desafios "no fogo cruzado" das relações familiares. Curitiba: Juruá.

Sousa, A. M. \& Brito, L. M. T. de. (2011). Síndrome de alienação parental: da teoria Norte-Americana à nova lei brasileira. Psicologia Ciência e Profissão, 31(2), 268-283.

Uziel, A. P. (2007). Homossexualidade e adoção. Rio de Janeiro: Garamond.
Verani, S. (1994). Alianças para a liberdade. In L. Brito (Org). Psicologia e Instituições e direito - a prática em questão (pp.14-20). Rio de Janiero: UERJ/Comunicarte/CRP-05.

Volpi, M. (1997). O adolescente e o ato infracional. São Paulo: Editora Cortez.

Weber, L. N. D. (2011). O psicólogo e as práticas de adoção. In H. S. Gonçalves \& E. P. Brandão. (Orgs.). Psicologia Jurídica no Brasil. $3^{a}$ edição (pp.141-174). Rio de Janeiro: Nau. 